\title{
Ageing and Health Services Use in Israel
}

\author{
Sigal Naim ${ }^{1}$ and Ariela Lowenstein ${ }^{2,3 *}$ \\ ${ }^{1}$ Department of Human Services, Yezreel Academic College, Israel \\ ${ }^{2}$ Department of Gerontology, Ben Gurion University in the Negev, Israel \\ ${ }^{3}$ Department of Gerontology \& Center for Research \& Study of Aging, The University of Haifa, Israel
}

*Corresponding author: Ariela Lowenstein, Department of Gerontology \& Center for Research \& Study of Aging, The University of Haifa, Yezreel Academic College, Haifa, Israel

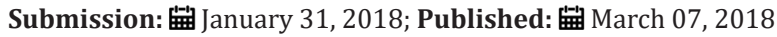

\section{Introduction}

Israel, as many other countries, must cope with issues that arise from demographic changes that are expressed both in the size and composition of the population. One of the prominent changes is in the age-structure of the society, which is especially influenced by the ageing of the population. Israel's population consists of $12.8 \%$ Jewish elders and $4.4 \%$ Arab elders. However, the proportion of disabled Jewish elders is $16 \%$ compared with $31 \%$ among Arab elders [1]. Disability leads to loss of independence, increases consumption of health services, and raises the cost of medical treatments. Among minorities, lower rates in health services use were found, since cultural differences are often not considered. Lack of sensitivity towards minority needs may lead to a gap between potential consumers and existing services [2-6].

Over the years it was found that improved accessibility of the low socio-economic population to health services has helped to reduce inequalities in health, and as a result, to reduce death rates [7]. For example, research findings show that minority groups have more economic barriers to accessible health services and accordingly are more restricted in their use [4]. It was found that, among minority groups in the population, it was possible to predict a low level of usage in formal professional services, including community health services. The findings link this with the fact that cultural differences are frequently not taken into considerations by the organizations that provide services. The lack of sensitivity for needs of the minority who should be consumers of the service is liable to cause a gap between potential customers and the offered services [3].

In our changing world one of the common barriers older people face is the use of modern technology to access numerous services including health services. Many organizations including community health organization adopt the digital channel as a main way of communication. Hence, individuals who are seeking such services are obliged to be digitally and technologically involved [6]. Thus, the ability to maintain active aging is impacted by elders' capabilities to use digital tools. Differences in digital literacy may cause inequalities among elders.
As a case study, we examined whether there are differences in use of community health services (acute hospitals and community health clinics) between two population groups: disabled older Jews and Arabs in later life; as well as investigated whether community health services use facilitate aging in place and social inclusion.

The study was based on Andersen's Behavioral Model for the consumption of health services [2]. 600 participants from Haifa and Northern Israel were interviewed - 150 disabled Jews and 150 disabled Arabs and their care-giving family members. The questionnaire included background variables, need variables and those related to the study model, like enabling variables such as Health Insurance policies and existing knowledge about health policy, and the WHO PROQOL BRF (1998) regarding their quality of life [7].

The findings reveal a positive correlation between background variables of the care-receivers and their health services use. A higher socio-economic status of the care-receiver and a higher level of knowledge is correlated with a higher level of health services used. A difference was found between level of health service usage, especially use of community health clinics, between Jewish and Arab care-receivers.

This case study discloses that regarding differences in health service usage may be related to better technological knowledge and use of online health services by the Jewish population as opposed to Arab elders. Apparently, inequality in health service usage might stem not only from accessibility but, in addition, from services adaptation to the specific culture and society in which they are provided [8]. This to encourage social inclusion of elders in later life, and by doing that enhancing quality of life. As studies have demonstrated that the older population are considered as late adopters of technology. Additionally, data in Israel have shown that Arab elders, and sometimes also their care giving families, are much behind in using technology, like connection to the Internet and its use. Hence, the health system should be more sensitive to cultural effects and minority elder groups and modify itself to answer needs of different ethnic groups within society [9]. 


\section{References}

1. Mashav (2016) The Elderly in Israel: Statistical Annual. Myers-JDC, Jerusalem, Israel.

2. Andersen R, Newman JF (1973) Social and individual determinants of medical care utilization in the United States. Milbank Mem Fund Q Health Soc 51(1): 95-124.

3. Azaiza F (2008) The perception and utilization of social support in times of cultural change: the case of Arabs in Israel. International Journal of Social Welfare 17(3): 198-203.

4. Henry J Kaiser Foundation (2007) Key facts: Race, ethnicity and medical care.
5. Brookdale Institute, Center for Ageing and ESHEL Research-Association for Planning and Developing Services for the Elderly in Israel.

6. Romero M, Hyvönen P, Barberà E (2012) Creativity in collaborative learning across the life span. Creative Education 3(4): 422-429.

7. Tamsma N (2008) Quality and equality of access to healthcare services. Country Report for the Netherlands.

8. World Health Organization (2007) World Health Statistics. India.

9. WHOQOL Group (1998) Quality of life assessment development and general psychometric properties. Social Science and Medicine 46: 1569 1585. (c) (1) Creative Commons Attribution 4.0

For possible submissions Click Here
Submit Article

\section{Gerontology \& Geriatrics Studies}

\section{Benefits of Publishing with us}

- High-level peer review and editorial services

- Freely accessible online immediately upon publication

- Authors retain the copyright to their work

- Licensing it under a Creative Commons license

- Visibility through different online platforms 